\title{
Molecular Mechanisms and Epigenetic Regulation in Diabetic Cardiomyopathy
}

\author{
Anupam Mittal ${ }^{1 *}$, Rajni Garg ${ }^{2}$, Ajay Bahl ${ }^{3}$ and Madhu Khullar ${ }^{4 *}$ \\ ${ }^{1}$ Department of Translational and Regenerative Medicine, Postgraduate Institute of Medical Education and Research, \\ Chandigarh, India, ${ }^{2}$ Council of Scientific and Industrial Research - Institute of Microbial Technology, Chandigarh, India, \\ ${ }^{3}$ Department of Cardiology, Postgraduate Institute of Medical Education and Research, Chandigarh, India, ${ }^{4}$ Department of \\ Experimental Medicine and Biotechnology, Postgraduate Institute of Medical Education and Research, Chandigarh, India
}

OPEN ACCESS

Edited by:

VijayaKumar Sukumaran Qatar University, Qatar

Reviewed by:

Rizwan Ahmed,

Johns Hopkins University, United States

Yu-Hsun Kao,

Taipei Medical University, Taiwan

*Correspondence: Anupam Mittal mittal.anupam@pgimer.edu.in Madhu Khullar madhu.khullar@gmail.com

Specialty section:

This article was submitted to Cardiovascular Biologics and Regenerative Medicine, a section of the journal

Frontiers in Cardiovascular Medicine

Received: 15 June 2021 Accepted: 15 November 2021 Published: 16 December 2021

Citation:

Mittal A, Garg R, Bahl A and Khullar M (2021) Molecular Mechanisms and Epigenetic Regulation in Diabetic Cardiomyopathy.

Front. Cardiovasc. Med. 8:725532.

doi: 10.3389/fcvm.2021.725532
Diabetes mellitus (DM) is an important lifestyle disease. Type 2 diabetes is one of the prime contributors to cardiovascular diseases (CVD) and diabetic cardiomyopathy $(\mathrm{DbCM})$ and leads to increased morbidity and mortality in patients with $\mathrm{DM}$. $\mathrm{DbCM}$ is a typical cardiac disease, characterized by cardiac remodeling in the presence of DM and in the absence of other comorbidities such as hypertension, valvular diseases, and coronary artery disease. $\mathrm{DbCM}$ is associated with defective cardiac metabolism, altered mitochondrial structure and function, and other physiological and pathophysiological signaling mechanisms such as oxidative stress, inflammation, myocardial apoptosis, and autophagy. Epigenetic modifiers are crucial players in the pathogenesis of DbCM. Thus, it is important to explore the role of epigenetic modifiers or modifications in regulating molecular pathways associated with $\mathrm{DbCM}$. In this review, we have discussed the role of various epigenetic mechanisms such as histone modifications (acetylation and methylation), DNA methylation and non-coding RNAs in modulating molecular pathways involved in the pathophysiology of the DbCM.

Keywords: diabetes mellitus, diabetic cardiomyopathy, apoptosis, oxidative stress, mitochondrial function, cardiac remodeling, epigenetics

\section{INTRODUCTION}

Diabetic cardiomyopathy (DbCM) is a cardiac disease characterized by functional and structural abnormalities in cardiac tissue in patients having diabetes mellitus (DM) but no other comorbidities such as hypertension, valvular diseases, and coronary artery disease (1). Framingham Heart Study observed that women and men with DM have 5- and 2.4-fold higher incidence of heart failure (HF), respectively (2). Patients with diabetes have a high prevalence of HF ranging from 19 to $26 \%(3-5)$. A case-control study found that the prevalence of HF was 1.3 times higher in diabetic subjects in comparison with the non-diabetic subjects (6). In both type I diabetes (T1D) and type II diabetes (T2D), patients showed a strong correlation between glycated hemoglobin $\mathrm{A}(1 \mathrm{c})$ (HbA1c) and HF. With every $1 \%$ increase in HbA1c, there is a 30 and $8 \%$ higher incidence of HF in T1D and T2D, respectively, independent of other risk factors $(7,8)$. The initial phase of DbCM is characterized by extensive cardiac hypertrophy and mild to moderate fibrosis, leading to defects in the systolic and diastolic function of the heart (9).

Experimental and clinical studies have identified sustained hyperglycemia (HG), insulin resistance, aberrant insulin signaling, impaired glucose metabolism, abnormal free fatty acid (FFA) uptake, oxidative stress, increased renin-angiotensin-aldosterone (RAAS) activity, cardiac 
inflammation, and aberrant mitochondrial function as the key determinants for biochemical alterations leading to a vicious cycle of disease. Cardiac fibrosis, left ventricular (LV) hypertrophy, and increased cardiomyocyte cell death are the most important mechanisms to explain the pathophysiology of the disease $(10,11)$. Multiple molecular mechanisms have been identified contributing to pathophysiological changes in DbCM (Figure 1), which include O-GlcNAcylation of cardiac proteins, decreased insulin and AMPK signaling, activated MAPK, peroxisome proliferator-activated receptors, and aberrant protein kinase $\mathrm{C}$ activity.

Recent studies suggest that epigenetic regulatory mechanisms such as DNA methylation, histone modifications (acetylation and methylation), deregulated microRNAs (miRNAs), circular RNA (circRNAs), and long non-coding RNA (lncRNAs) play an important role in the pathogenesis of $\operatorname{DbCM}(12,13)$. In this review, we provide a comprehensive overview of the role of epigenetic modifications in various molecular pathways associated with DbCM.

\section{MOLECULAR MECHANISMS AND THEIR EPIGENETIC REGULATIONS IN DbCM}

\section{Cardiac Remodeling in DbCM}

Cardiomyocyte hypertrophy and fibrosis are the important features of DbCM. Cardiac fibrosis is a dominant mechanism contributing to the disease pathology of the diabetic human heart. There is a very pronounced deposition of collagen in interstitial and perivascular spaces in diabetic cardiac tissues (14). The major contributing pathways for the aggravated deposition of collagen types I and III are transforming growth factor- $\beta 1$ (TGF- $\beta 1$ ) and wingless-related integration site (WNT) signaling pathways (15). Additionally, there is remodeling of matrix metalloproteinases (MMPs) leading to dysregulated degradation of extracellular matrix in diabetic hearts (15-18). Activation of the TGF- $\beta 1$ pathway and accelerated extracellular matrix degradation are mainly consequences of stimulation of RAAS resulting in heightened advanced glycation end products (AGEs)-mediated signaling, HG, and insulin resistance (19). Decreased availability of nitric oxide (NO), oxidative stress, activation of TGF- $\beta 1$ signaling pathway, in association with deregulated insulin signaling leads to high cardiac collagen deposition and fibronectin content, leading to interstitial fibrosis (20). Several clinical and animal studies provide substantial evidence of cardiac fibrosis in diabetes-induced heart failure (HF) (18, 21-23).

An increase in LV hypertrophy represented by high LV mass and its association with DM is well-established (24-26). Thickened LV is a major hallmark of cardiac hypertrophy in humans (27). Cardiac fibrosis, hypertrophy, and myocardial cell apoptosis must be taken into account for the overall increase in $\mathrm{LV}$ mass $(27,28)$. In $\mathrm{DbCM}$, there are other contributors in addition to cardiac hypertrophy such as insulin resistance, $\mathrm{HG}$ in the milieu, and oxidative stressactivating cardiac hypertrophic genes, such as $\beta$-myosin heavy chain (B-MHC), atrial natriuretic factor (ANP), and brain natriuretic factor (BNP) (29). Heightened insulin levels induce cardiac hypertrophy. Insulin-like growth factor (IGF-1) induces cardiomyocyte hypertrophy through activation of the mitogenactivated protein kinase 1 (Erk1/2) and phosphoinositide 3kinases (PI3K) signaling pathways (30). Several studies in animal models of DbCM have also shown the role of DM in the development of cardiac or cardiomyocyte hypertrophy (31-33).

\section{Epigenetic Regulation of Cardiac Remodeling in DbCM}

MicroRNAs are small, non-coding RNAs, which regulate cellular gene expression. Aberrant expression of $\sim 30 \%$ miRNAs (that is 300 out of 1,000 total miRNAs) has been observed in DM heart tissues (34). Several miRNAs have been found to regulate cardiac fibrosis and cardiac hypertrophy in DbCM. For example, miRNA-221 was shown to be highly upregulated in the cardiac tissue of diabetic mice (35). miRNA-212 was found to regulate the process of cardiac hypertrophy by directly regulating Forkhead box O3 (Foxo3) (35). Raut et al. reported that miRNA-30c mediates increased expression of hypertrophy genes, cell division control protein 42 homolog (Cdc42), and Rac1-activated kinase 1 (Pak1) in DbCM (36). Other miRNAs, such as 181a and 200c, were shown to play a pivotal role in cardiac remodeling (35, 37-39). The expression of miRNA-199a was elevated in cardiac hypertrophy (34). Recently, it was reported that silencing of miR-199a led to the reversal of cardiac hypertrophy by rescuing the mitochondrial fatty acid oxidation through targeting peroxisome proliferator-activated receptor-gamma coactivator (PGC-1 $\alpha$ ) (40). miRNA-30a, miRNA-1, and miRNA-29b levels were found to be downregulated in the diabetic heart (34). miRNA-144 and miRNA-133a are among the important key players, involved in the pathophysiology of diabetes-mediated HF $(41,42)$. Singh et al. showed that miRNA-200c promoted cardiac hypertrophy by modulating dual-specific phosphatase 1 (DUSP1) expression in DbCM (39).

Decreased levels of miRNA-133a were observed in the diabetic murine model (43). It was also seen that increase in miRNA133a levels improved the systolic function and reduced fibrosis by decreasing the collagen (44). miRNA-21 has been established as a biomarker for cardiac fibrosis (45). Several groups including ours have shown upregulated miRNA-21 levels in rat cardiac fibroblasts in the hyperglycemic milieu and in diabetic hearts, which leads to advanced collagen synthesis and fibroblast proliferation $(46,47)$. miRNA-21 was also found to directly regulate dual-specific phosphatase 8 (DUSP8) by perturbing cJun N-terminal kinase (JNK) and p38 MAP kinase (MAPK) signaling pathways (46).

Long non-coding RNAs, a type of non-coding RNAs which are longer than miRNAs, have been implicated in various disease pathways (48). Nuclear lncRNAs act at the transcriptional level, and cytoplasmic lncRNAs often interact with miRNAs to regulate gene expression post-transcriptionally. Several lncRNAs have been recently shown to be involved in the pathophysiology of CVDs, including DbCM, contributing to cardiac hypertrophy and fibrosis. Myocardial infarctionassociated transcript (MIAT) acts as prohypertrophic lncRNA as it has a sponging activity for antihypertrophic miRNAs, 


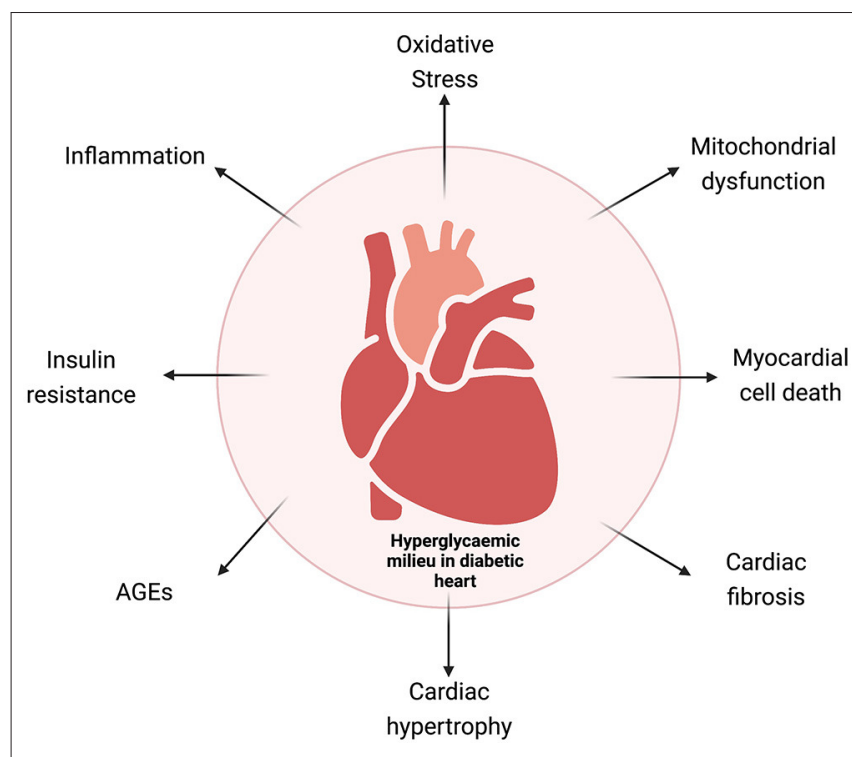

FIGURE 1 | Schematic representation of the various mechanisms involved in diabetic cardiomyopathy. AGEs, advanced glycation end products.

miRNA-150 (49), and miRNA-93 (50). Additionally, MIAT levels were higher in the myocardium and compete with miRNA-24 levels to regulate TGF- $\beta 1$ expression and thus cardiac fibrosis (51). LncRNA Kcnq1ot1 ablation ameliorates TGF- $\beta 1$ signaling and, thus, reduces fibrotic lesions in diabetic mice (52). The dysregulated ncRNAs, both miRNA and lncRNA, explain HGrelated myocardial insult.

Histone modifications also have been found to play a crucial role in the cardiac remodeling in DbCM. Non-specific inhibitorbased silencing of histone deacetylases (HDACs) has been shown to attenuate cardiac hypertrophy and fibrosis, by increasing the glucose transporter 1 acetylation and MAPK-mediated phosphorylation in animal models of diabetic heart disease (53). The use of specific HDAC3 inhibitors such as RGFP966 also showed improved cardiac function and reversed DM-induced cardiac remodeling in diabetic mice. It was found that RGFP966 decreased cardiac hypertrophy by epigenetic modulation of the ERK1/2 pathway mediated by DUSP5 (54). In contrast, Sir2 is known to have a beneficial effect on DCM. It improves contractile dysfunction in leptin receptor-deficient $\mathrm{db} / \mathrm{db}$ mice through a histone deacetylase Sir2-driven pathway (54), suggesting its potential as a therapeutic molecule in DbCM. (55).

\section{Role of Epigenetics in Regulating Cell Death Mechanisms in DbCM}

Diabetic cardiomyopathy has a strong association with high cardiomyocyte cell death. Apoptosis and autophagy are the important deregulated mechanisms responsible for this phenomenon (56). Several fold higher apoptosis rates have been reported in cardiomyocytes, fibroblasts, and endothelial cells in myocardial tissues of patients with DbCM. The death rate of cardiomyocytes was the highest, followed by that of endothelial cells and fibroblasts (57). Increased cardiomyocyte cell death results in cell loss in the heart, remodeling such as cardiac hypertrophy and fibrosis, leading to cardiomyopathy and cardiac failure (58).

Various mechanisms are proposed for increased cardiomyocyte cell death in diabetic hearts. HG, insulin resistance, lipid peroxidation, increased angiotensin II signaling, oxidative stress, and endoplasmic stress have been implicated as major triggers of cardiomyocyte apoptosis in the diabetic milieu. HG is the major causative factor for increased oxidative stress and endoplasmic stress mediating cardiomyocyte death in diabetic hearts (59). HG mediates these actions through localized increased angiotensin II (Ang II) (60). Kobayashi et al. have recently shown that $\mathrm{HG}$ may also induce cardiomyocyte cell death by inducing lysosomal membrane permeabilization and increased cathepsin D expression and lysosomal release in cardiomyocytes resulting in cell death (61).

\section{Apoptosis and Its Epigenetic Regulation}

The expression of several miRNAs was deregulated in HGinduced cardiomyocyte apoptosis and diabetic hearts (34). These include miRNA-30c, miRNA-181, miRNA-378, miRNA34a, miRNA-1, miRNA-195, miRNA-144, and miRNA-483-3p. It was shown that miR-1 is upregulated in HG-treated H9c2 cardiomyocytes along with increased apoptosis. They reported that miR-1 promotes cardiomyocyte apoptosis by inhibiting IGF-1 expression; IGF-1 increased expression was shown to inhibit glucose-induced cytochrome c release and apoptosis, suggesting that miRNA-1 promotes apoptosis by regulating IGF1 (62). miRNA-34a is highly expressed in cardiomyocytes and regulates the expression of several proteins including prosurvival protein, sirtuin 1 (SIRT1). miRNA-34a is upregulated in diabetic hearts and glucose-treated cardiomyocytes. Fomison-Nurse et al. reported that upregulation of miRNA-34a was associated with downregulation of SIRT1 and increased the activity of proapoptotic caspases in HG-treated cultured cardiomyocytes. Inhibition of miRNA-34a was found to reduce HG-induced cardiomyocyte apoptosis, indicating its potential therapeutic role (63). Qiao et al. showed that miRNA-483-3p was involved in HGinduced cardiomyocyte apoptosis by repressing the expression of its target gene, IGF-1. They reported elevated expression of this miRNA in diabetic mice and hyperglycemic cardiomyocytes (64). Downregulation of miRNA-30c and miRNA-181 was observed in diabetic hearts and hyperglycemic cardiomyocytes (38). These miRNAs promote cardiomyocyte apoptosis by deregulation of a p53-p21 axis (38). It was reported that miRNA-195 upregulation induces apoptosis in streptozotocin (STZ) and leptin receptordeficient type 2 diabetic murine hearts via downregulation of SIRT1 and B cell leukemia 2 ( Bcl2) (65). Altered expression of miRNA-144 was observed in hearts and also cardiomyocytes in hyperglycemic conditions. miRNA-144-3p was found to be upregulated in T2D (66). Karolina et al. reported that miRNA144 controls the expression of IRS-1 in diabetes (66). Recently, Song et al. have reported increased miRNA-144 levels in HGtreated cardiomyocytes (67). They showed that miRNA-144targeted C1q/TNF-related protein 3 (CTRP3)/JNK pathway and inhibition of miRNA-144 attenuated cardiomyocyte apoptosis. In another study, Tao et al. observed decreased miRNA-144 levels in HG-treated cardiomyocytes and diabetic hearts (68). 
Cellular overexpression of miRNA-144 resulted in improved mitochondrial function and decreased myocyte apoptosis by regulating Rac family small GTPase 1 (Rac-1) levels, which in turn regulated apoptosis via 5' AMP-activated protein kinase (AMPK) phosphorylation and PGC-1 $\alpha$ deacetylation (68). Thus, the precise role of this miRNA remains to be fully elucidated. Altered PI3K/Akt signaling stimulates apoptosis, fibrosis, and hypertrophy of cardiomyocytes and leads to DbCM progression (69). It was reported that miRNA-203 overexpression inhibited PIK3CA and activated of PI3K/Akt signaling, thus inhibiting myocardial hypertrophy, fibrosis, and apoptosis (69). Recently, miRNA-532 has been shown to exhibit a positive association with cardiomyocyte apoptosis in diabetic heart disease. miRNA-532 was shown to be upregulated in cardiac tissues of patients with type $2 \mathrm{DM}$, thus decreasing the expression of its main target, the antiapoptotic protein (ARC). It was shown that miRNA532 upregulation leads to the activation of proapoptotic caspases activity and vice versa in HG-treated cardiomyocytes (70). Another study showed decrease in expression of antiapoptotic protein, Hsp60 in the diabetic heart. miRNA-1 and miRNA206 modulated myocardial Hsp60 post-transcriptionally and its downregulation was an important proapoptotic signal in the diabetic myocardium (71).

Besides miRNAs, several lncRNAs have been identified mediating cardiac cell death in hyperglycemic or diabetic conditions (72). Decreased expression of lncRNA H19 in DCM and HG-treated cardiomyocytes was observed and improved ventricular function by inhibiting reduced apoptosis in diabetic rats (73). H19 functions by inhibiting miR-675-mediated expression of voltage-dependent anion channel 1 (VDAC1), a proapoptotic molecule, which promotes cell death (73). Yang et al. showed escalated expression of another lncRNA Kcnq1ot, in the hearts of diabetic mice. They further showed that inhibition of Kcnq1ot1 improved cardiac function and attenuated pyroptosis (52). Metastasis-associated lung adenocarcinoma transcript 1 (MALAT1) is another long non-coding RNA that regulates HGinduced cardiomyocyte apoptosis (74). MALAT1 was also shown to downregulate miR-141 or miR-181a-5p levels by sponging and inducing NLR family pyrin domain containing 3 (NLRP3) inflammasome activity and TGF- $\beta 1 /$ Smad signaling (75). In a very recent study, MALAT1 has been shown to influence cardiomyocyte apoptosis by EZH2, a histone methyltransferase, and upregulating ATP-binding cassette transporter A1 (ABCA1) (76). HOTAIR is another IncRNA that has been shown to protect cardiac cell death in hyperglycemic conditions and DbCM. HOTAIR was decreased in the hearts of the diabetic mice, and its cardiac-specific overexpression attenuated cardiomyocyte death in STZ diabetic mice (77). It was shown to regulate miR-34a levels by acting as competing endogenous RNA (ceRNA) and increasing its target protein SIRT1, which has antiapoptotic activity (77). MEG3 is a lncRNA that is upregulated in HG-treated cardiomyocytes and induces apoptosis via sponging miR-145 and increasing proapoptotic programmed cell death 4 (PDCD4) levels (78). Recently, expression of Lnc NKILA (nuclear factor- $\kappa \mathrm{B}$ interacting long non-coding RNA) was found to be highly increased in patients with $\mathrm{DbCM}$ and its in vitro silencing decreased HG-induced cardiac cell death (79). Similarly, increased lncRNA LUCAT1 (lung cancer-associated transcript 1) levels were found in HGtreated AC 16 cardiomyocytes and its inhibition reduced HGinduced cardiomyocyte apoptosis by downregulating aldosterone synthase (CYP11B2) (80).

The DNA and histone methylation and acetylation are important epigenetic mechanisms that regulate gene expression and associated cellular mechanisms. The role of these mechanisms in diabetic cardiomyocyte cell death has not been well-investigated but emerging research suggests that they might have an important role. Yu et al. reported that HDAC1 mediates repression of IGF-1R in HG-treated cardiomyocytes (81). They showed that the association of histone 4 with p53-HDAC1 is increased and the association of histone 4 with IGF-1R is decreased (81). HDAC inhibition was later shown to inhibit HG-induced cardiac apoptosis by increasing GLUT1 acetylation and decreasing caspase 3 activity in diabetic mice (53).

Endoplasmic reticulum (ER) stress, an important mediator of $\mathrm{DbCM}$, has also been implicated in the induction of apoptosis of cardiac cells (82). The role of epigenetic regulation of ER stress in DM-induced cardiac apoptosis was further confirmed by Guo et al. They reported that activation of SIRT1, a deacetylase, attenuates ER stress and apoptosis in cardiomyocytes of diabetic rats (83). Nitrosative stress induced by increased nitric oxide production resulting in nitrosylation of proteins has been found to induce apoptosis in heart of diabetic rats (84). Puthanveetil et al. reported that HC-induced iNOS expression in cardiomyocytes leads to increased nitrosylation of caspase 3 that facilitates apoptosis. They showed that nitrosylation of the proteins was mediated by Foxo1. Foxo1-mediated nitrosylation of caspase 3 resulted in increased cell death under HG conditions (84).

\section{Autophagy and Its Epigenetic Regulation}

Autophagy is a physiological process that removes or recycles damaged cell components such as organelles, proteins, and metabolites from the cell. It is an important process to maintain cell homeostasis. Both repression and augmentation of autophagy have been reported in diabetic hearts and HGexposed cardiomyocytes (85-87). Mellor et al. reported increased autophagy (LC3B-II: LC3B-I ratio) in hearts of fructose-fed diabetic mice, suggesting myocardial autophagy activation in DbCM (88). However, Xie et al. reported repressed cardiac AMPK activity and autophagy in OVE26 diabetic mice (89). To date, there is no unequivocal consensus on the role of myocardial autophagy in the pathophysiology of DbCM. A recent review on autophagy in diabetic heart showed that autophagy might act as a double-edged sword, with initial activation helping in the removal of damaged mitochondria, peroxisomes, and protein aggregates and improving antioxidant mechanisms through the activation of antioxidant transcription factors such as nuclear factor erythroid 2-related factor 2 (Nrf2). However, this increased autophagy in the cell may result in self-digestion and enhanced reactive oxygen species (ROS) generation, causing cardiac damage (87).

Few reports suggest that miRNAs may regulate diabetesinduced autophagy. Chen et al. reported that circulatory miRNA30c levels were highly reduced in patients with DM. Similar 
results have been found in an animal model of diabetes and cardiomyocytes. It was observed that miR-30c directly regulates Beclin-1 expression. Thus, downregulation of miR-30cenhanced autophagy by increasing proautophagic Beclin-1 expression in diabetic hearts. Further, miR-30c directly regulates Beclin-1, thus controlling autophagy in DM (90).

There are a few studies suggesting the involvement of LncRNAs in DbCM. Feng et al. showed a marked increase in expression of LncRNAs, DCM-related factor (DCRF) in DbCM in the diabetic mice model (91). They showed that DCRF increased cardiomyocyte autophagy by sponging miR-551b$5 \mathrm{p}$, thereby increasing protocadherin 17 (PCDH17) expression (89). Similarly, Zhou et al. reported decreased expression of LncRNA H19 in DbCM. They observed that LncRNA H19 regulates GTP-binding protein Di-Ras3 (DIRAS3) expression and promotes mTOR phosphorylation, thus inhibiting autophagy in DbCM (92).

\section{Pyroptosis and Its Epigenetic Regulation}

Pyroptosis or inflammation-induced cell death has been shown to contribute to increased cardiomyocyte cell loss in DbCM (93). miRNA-30d promoted cardiomyocyte pyroptosis in hyperglycemic conditions by repressing Forkhead box $\mathrm{O} 3$ (Foxo3a) and its downstream effector activity regulated cytoskeleton-associated protein (ARC), an apoptotic repressor leading to caspase- 1 activation and increasing proinflammatory molecules (94). Jeyabal et al. have also reported that miRNA9 may have a role in HG-induced cardiomyocyte pyroptosis (95). They showed that expression of miRNA-9 was significantly decreased in HG-treated cardiomyocytes in vitro and in human diabetic hearts in vivo. The proinflammatory ELAV-like protein 1 (ELAVL1) was shown to be the target protein of miRNA-9. The authors reported that upregulation of miRNA-9 attenuated HGinduced cardiomyocyte pyroptosis by downregulating ELAVL1 expression, indicating that miRNA-9 has an antiapoptotic role in diabetic hearts (95).

\section{Epigenetic Regulation of Mitochondrial Dysfunction in DbCM}

Mitochondria play a vital role in the maintenance of cardiac function and metabolism. Loss of mitochondrial function is implicated in DbCM (96). In adult cardiomyocytes, oxidative phosphorylation is the major source of intracellular ATP production in mitochondria. During DM, there is a switch in the ATP production pathway from glucose to FFA oxidation in mitochondria (97). This impaired oxidative phosphorylation increases mitochondrial ROS generation (98). Further, faulty $\mathrm{Ca}^{2+}$ flux in mitochondria leads to apoptosis in cardiomyocytes (99). This dysregulated $\mathrm{Ca}^{2+}$ flux also induces permeability in mitochondrial membranes, resulting in increased cardiomyocyte autophagy (100).

MicroRNAs have a significant role in fatty acid metabolism in the diabetic heart tissues. miRNA-133a levels were decreased in the cardiac tissue of the diabetic murine model (43). Mechanistically, miRNA-133a controls the CD36 expression by directly regulating testicular protein 4 (101). This explains the increase in CD36 expression in diabetic rat hearts (102).
Peroxisome proliferator-activated receptor alpha (PPAR- $\alpha$ ) regulates the oxidation of fatty acids in cardiomyocytes (103). miRNA-29a directly regulates the coactivator of PPAR- $\alpha$ (104). It was also reported that miRNA-29a levels are decreased in diabetic rat hearts, and this explains the increased fatty acid oxidation mediated by PPAR- $\alpha$ (105). In another study, it was reported that miRNA-210 levels are 2.5 folds higher in human diabetic failing hearts compared with non-diabetic failing hearts (106). miRNA-210 is a direct regulator of ISCU1/2, iron sulfur complex protein, which drives the electron transport chain (ETC) by regulating the function of aconitase and complex I (107). Another group reported that there is an increase in miRNA141 levels in type 1 diabetic hearts (108). miRNA-141 regulates inorganic phosphate transport in the mitochondria by regulating the solute carrier family 25 members 3 (SLC25A3), this, in turn, affects the ATP synthesis in mitochondria (108). Similarly, miRNA-378 that negatively regulates ATP synthase was found to be elevated in interfibrillar mitochondria in streptozotocininduced diabetic hearts of mice (109). All studies suggest that miRNAs are important players in mitochondrial function and energy metabolism in the diabetic heart.

Histone modifiers such as deacetylases and acetyltransferases regulate global acetylation levels in various physiological states of the cell. They maintain homeostasis by acetylation or deacetylation of histone substrates (110). It was reported that increased HDAC activity leads to myocardial ischemia mediated by Foxo3a/Bim in the diabetic heart (111). Well-known cardiac protector resveratrol reduces mitochondrial dysfunction through regulation of SIRT1 activation in a murine model of DM and increased histone deacetylation of PGC- $1 \alpha(112,113)$. In the murine model of DM, HDAC inhibition resulted in elevated expression of cardiac PPAR- $\alpha$ and resulted in reduced expression of peroxisome proliferator-activated receptor gamma (PPAR- $\gamma$ ), suggesting the role of HDAC abrogation in regulating the fatty acid oxidation in DbCM (114).

\section{Mitochondrial Oxidative Stress and Its Epigenetic Regulation in DbCM}

Oxidative stress plays a crucial role in the pathogenesis and progression of $\mathrm{DbCM}$ by increasing insulin resistance in cardiomyocytes (Figure 2). During oxygen metabolism in mitochondria, ROS is produced as a by-product (97). Under abnormal conditions such as insulin resistance and HG, there is an increase in $\mathrm{NADH}$ in the mitochondrial respiratory chain leading to shunting of ETC at complex III and leading to tremendous ROS production (115). High NADPH oxidase activity is seen in cardiomyocytes of patients with obesity and cardiac insulin resistance (31). This increase in NADPH oxidase activity led to increased ROS generation. In DbCM, ROS levels also get elevated because of increased xanthine oxidase activity and NO synthase uncoupling (116). Mitochondrial dysfunction leads to increased ROS accumulation. Major ROS determinants are hydrogen peroxide, hydroxyl radical, superoxide molecules, and reduced oxygen in patients with DbCM (116-118).

Several miRNAs such as miRNA-1, miRNA-19b, and miRNA-144 have been associated with oxidative stress $(34,41)$. 


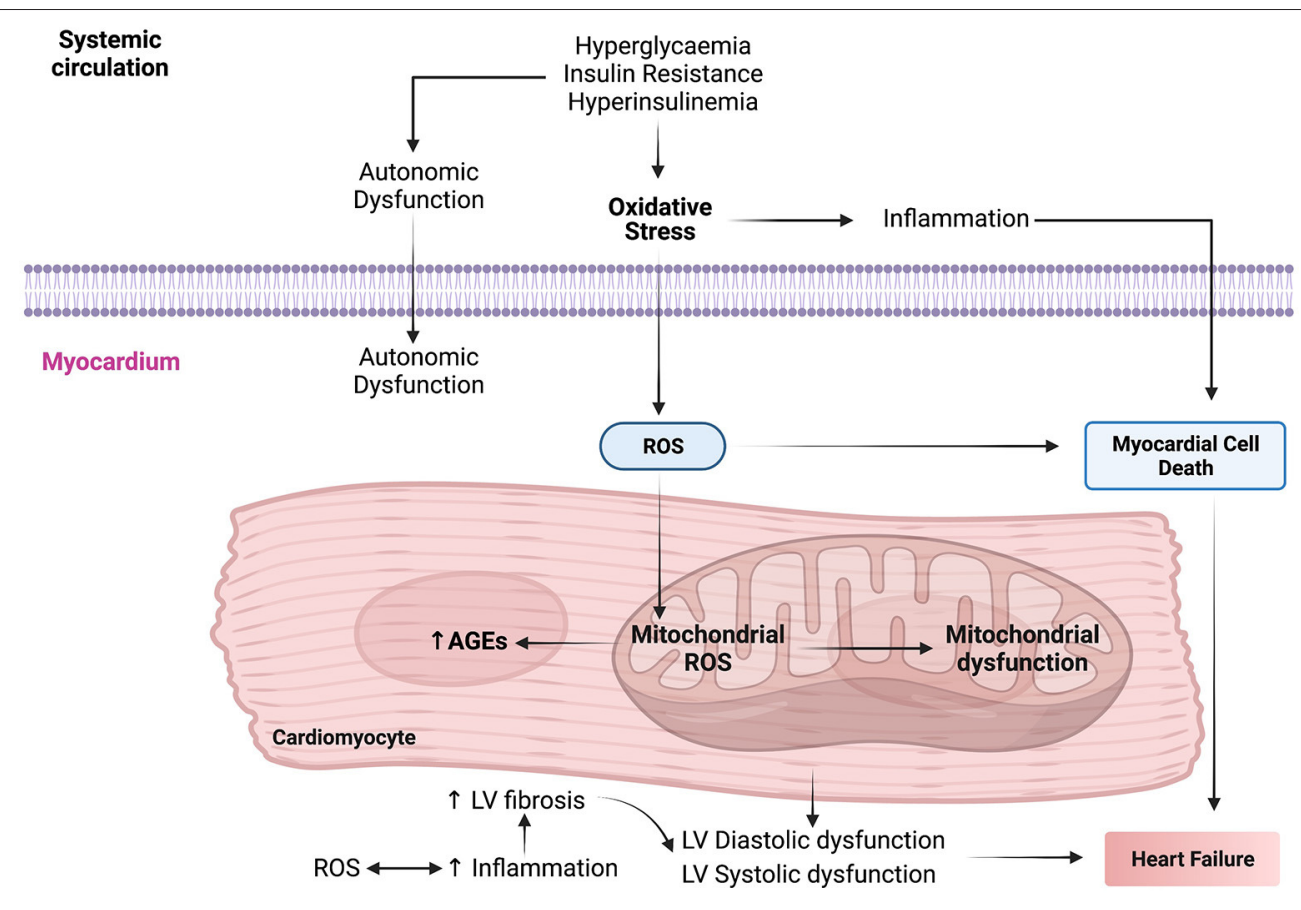

FIGURE 2 | The molecular mechanisms interactome in the pathophysiology of diabetic cardiomyopathy (DbCM). AGEs, advanced glycation end products; LV, left ventricle; ROS, reactive oxygen species.

It was shown that miR-1 levels decrease in cardiomyocytes treated with high glucose and treatment with $\mathrm{N}$-acetylcysteine (NAC) leads to the rescue of cardiac phenotype proving the role of miRNA in oxidative stress-dependent DbCM (119). Similarly, miRNA-144 levels were found to be downregulated in hyperglycemic conditions. miRNA-144 is shown to regulate ROS levels directly through Nrf2 expression (41). Moreover, an increase in miRNA-141 in type I diabetic mice heart inhibited mitochondrial phosphate carrier (Slc25a) resulting in increased ROS and decreased mitochondrial ATP generation (108). Additionally, miRNA-210 has been reported to regulate mitochondrial metabolism by targeting the molecules involved in the ROS generation (120). Another report suggests that miRNA-373 levels were decreased in $\mathrm{DbCM}$ due to glucose-induced oxidative stress-mediated cardiac hypertrophy (121).

Few lncRNAs have been reported to regulate diabetes-induced oxidative stress. LncRNA H19 was shown to be downregulated in diabetic rat hearts, and enforced overexpression leads to attenuation of oxidative stress and thus, in turn, alleviates the LV dysfunction (73).

Epigenetic modulators such as histone DNA deacetylases have been also found to play an important role in oxidative stress-mediated pathophysiology of DbCM. Kumar et al. reported that dysregulated SIRT1 and methyltransferase $3 \mathrm{~b}$ (Dnmt3b) activity resulted in increased histone $\mathrm{H} 3$ acetylation and $\mathrm{CpG}$ demethylation at the p66Shc (prooxidant adaptor protein) promoter in diabetes-induced vascular oxidative stress $(122,123)$. Similarly, Mortuza et al. looked into the mechanisms that decreased SIRT1 activity and suggested the role of SIRT1 and FOXO1 axis in ROS-mediated stress (124).

\section{Electrical Remodeling and Its Epigenetic Regulation in the Progression of $\mathrm{DbCM}$}

Structural cues such as cardiac remodeling (fibrosis and hypertrophy) lead to functional abnormality (altered electrical activation) ultimately leading to electrical remodeling of the heart during HF. Electrical remodeling is characterized by compensatory or maladaptive prolonged disturbances in ion channels that might be reversible or irreversible, respectively. The remodeling of the electrical conduction system is considered to be the main reason for lethal arrhythmias (125). There are various etiologies of CVDs but delay in cardiac action potential repolarization is a common mechanism of electrical remodeling (125-127). Most electrophysiological studies suggest that a dip in the $\mathrm{K}+$ currents plays a key role in electrical remodeling (126129). There is experimental evidence suggesting that alterations in glucose metabolism in cardiomyocytes led to the remodeling of various channels in the ventricle. It will be interesting to learn that how the $\mathrm{K}+$ channel gets altered in DM. Mechanisms behind the upregulation of $\mathrm{K}^{+}$channel activity in cardiomyocytes of patients with DbCM have derailed insulin signaling and glucose utilization. It was shown in the streptozotocin-induced DM murine model that insulin treatment is quite promising in achieving the normal transient outward current (129-131).

In the case of DbCM (induced by type I or type II diabetes), prolonged QT is seen (132-135), increasing the risk of ventricular arrhythmia $(136,137)$. At the molecular level, this lengthening of 
the action potential is mainly driven by deregulated expression of various ion channel proteins and their properties (138-140).

Recently, it was found that epigenetic regulators such as miRNAs also participate in myocardial electrical remodeling (141). The expression of voltage-gated potassium channel Kv4.2 is regulated by miR-301a in diabetes (141). Overexpression of miRNA-29 in the diabetic murine model led to structural damage in the heart (142). In another study using a murine model of diabetes, it was seen that an increase in miRNA-141 levels affects ATP production by decreasing mitochondrial phosphate transport (108).

Various studies have underscored the role of HDACs in the regulation of ion channel expression but their exact function still needs to be elucidated. One such study elucidates the regulation of sodium-calcium exchanger (NCX)1 by HDAC5. The NCX1 is involved in $\mathrm{Ca}^{2+}$ efflux out of the cells and its expression is regulated by NK2 homeobox 5 (NKX2.5). It is involved in the recruitment of HDAC5 to the NCX gene promoter (143). Another study showed that acetylation of NKX2.5 increases its interaction with HDAC5, whereas deacetylation of NKX2.5 increases its affinity toward the p300 complex (144). Epigenetic regulation of HDACs affects $\mathrm{Ca}^{2+}$ flux in cardiomyocytes (145). In this study, the authors reported that the N-terminal of HDAC4 inhibits MEF2 activity, resulting in reduced expression of nuclear orphan receptor NR4A, suppressing the hexamine biosynthetic pathway (145). HDAC2 was downregulated in the porcine model of HF, affecting the potassium channel and prolonging the QT interval (146), leading to inhibition of HDAC2 and affecting the action potential. Inhibition of HDACs using class I inhibitor entinostat is a plausible therapeutic modality for $\mathrm{HF}$ that reduces the electrical and structural remodeling in HF (147).

\section{Histone Deacetylases Inhibitors: A Prospective Therapeutic Modality for $\mathrm{DbCM}$}

Histone deacetylases are molecules with pleiotropic function and are involved in crucial homeostatic processes such as proliferation, cell death, and cell cycle. HDAC inhibitors (HDACIs) specifically block $\mathrm{Zn}^{2+}$-dependent HDAC enzymes involved in histone acetylation. Recently, the US FDA has approved HDACIs for cancer treatment in clinics (148). Moreover, few reports suggest that regulation of histone acetylation is a promising strategy for the treatment of cardiovascular disease in the preclinical model (149). HDACIs are divided into five categories based on their structure:

A) Hydroxamic acid derivates: (e.g., panobinostat, trichostatin A)

B) Short-chain fatty (aliphatic) acids (e.g., valproic acid (VPA), sodium butyrate)

C) Cyclic peptides (e.g., romidepsin)

D) Benzamides (e.g., entinostat)

E) Sirtuin inhibitors

These HDACIs have been approved by US FDA (150-152). To date, HDACIs are not used in clinical trials for fibrotic diseases, but they have been used in cardiac and lung fibrosis (153-155). The major player in the fibrotic condition is the transition of fibroblast into myofibroblasts (156). There are studies suggesting that HDACIs have reversed myofibroblasts activation in animal models of HF. VPA combated fibrosis in the hypertension murine model by regulating the acetylation of corticoid receptors (157). In the pressure overload mice model, VPA abrogated cardiac remodeling (158). VPA also ameliorated cardiac fibrosis by regulating the ERK1/2 phosphorylation (159). A recent study demonstrated that VPA decreased the remodeling process, therefore leading to the onset of atrial fibrillation (160). Similarly, pan-HDACIs also showed antifibrotic activities, MPTOE014 decreased the expression of Ang II and TGF$\beta$ receptors in a murine model of cardiomyopathy (161). Mocetinostat downregulated the expression of HDACs in an HF model mechanistically by increasing apoptosis and reducing the myofibroblast phenotype (162). HDAC6 silencing or inhibition using tubacin reduced the TGF- $\beta 1$ expression and, thus, decreased cardiac fibrosis (163). There is a need for more comprehensive studies looking into the potential of selective HDACIs for DbCM treatment.

\section{CONCLUSION AND FUTURE PROSPECTIVE}

Diabetic cardiomyopathy is a pleiotropic metabolic disease, with complex etiology and cumulative effects of crosstalk between genetic and epigenetic factors. The diabetic milieu has several inducers of cardiomyopathy such as ROS-mediated oxidative stress, hyperglycemic conditions, cytokines-mediated inflammation, cell death (apoptosis, autophagy, and pyroptosis), and epigenetic regulation of the dysregulated molecular pathways induced by these mediators. Epigenetic modifications range from deregulated ncRNAs (miRNAs and lncRNAs), histone modifications (acetylation and methylation), and DNA promoter methylation, which regulates the expression of important molecules of various pathways mediating DbCM. In summary, previous studies showed that interaction between environmental and genetic factors strongly determine the pathogenesis of $\mathrm{DbCM}$ through epigenetic changes in cellular signaling pathways (Figure 3).

The past decade has shown that miRNAs and lncRNAs are important regulators of major molecular pathways such as cell death, oxidative stress, mitochondrial dysfunction, and electrical remodeling (Tables 1, 2). Cardiac fibrosis is an important phenomenon of the cardiac remodeling process in DbCM. There is substantial evidence that epigenetics plays a major role in diabetes-associated cell death. Epigenetic regulatory mechanisms such as histone changes, DNA methylation, miRNAs, and non-coding RNAs regulate cardiac cell death in the diabetic milieu. Similarly, other mechanisms such as mitochondrial dysfunction, oxidative stress, and electrical remodeling are also regulated by miRNAs and by HDACs. The elucidation of these epigenetic mechanisms can provide newer therapeutic strategies for the DbCM. miRNAs and lncRNAs have shown 


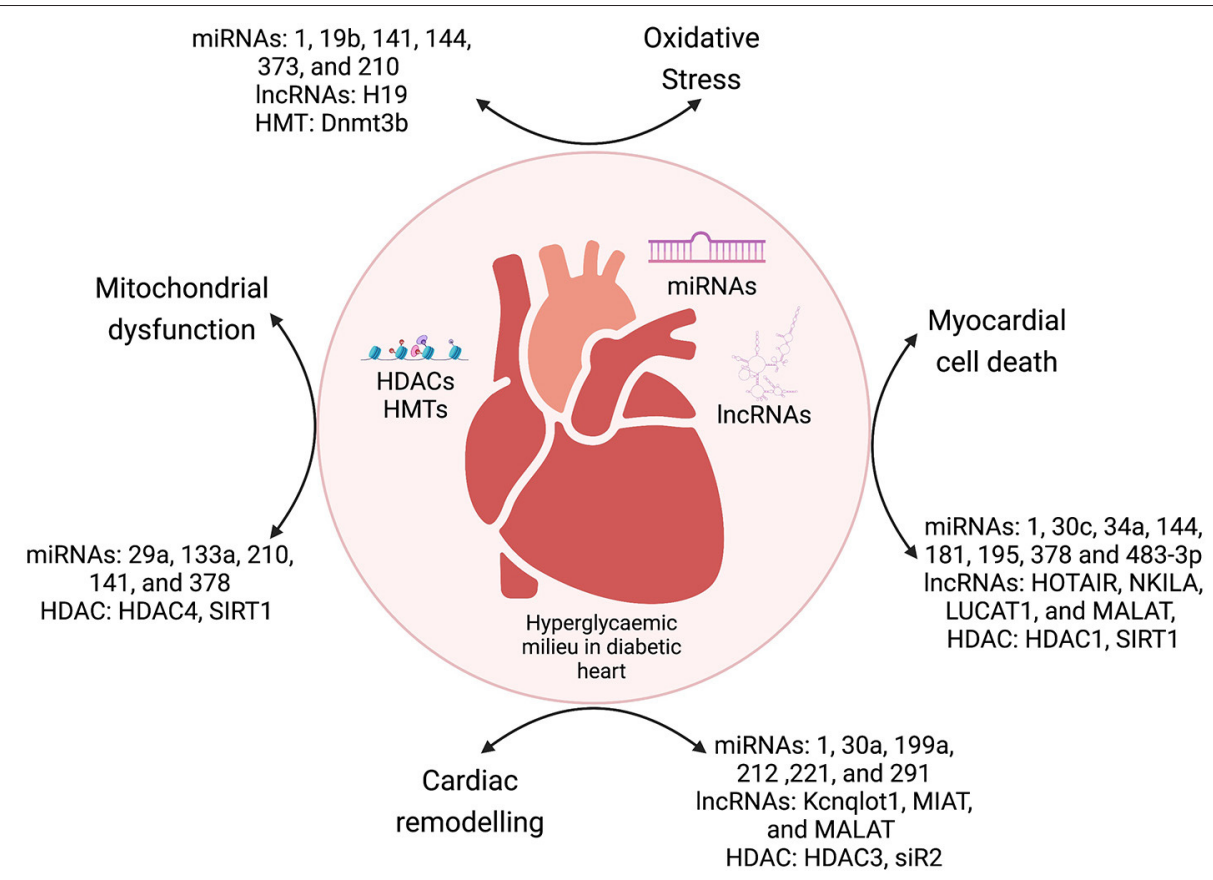

FIGURE 3 | The crosstalk between epigenetic modulators and various mechanisms of DbCM. miRNAs, microRNAs; IncRNAs, long non-coding RNAs; HDACs, histone deacetylases; HMTs, histone methyltransferases; DNMT, DNA methyltransferases.

TABLE 1 | Deregulated miRNAs in diabetic cardiomyopathy (DbCM).

\begin{tabular}{|c|c|c|c|}
\hline miRNAs & Process associated & Target genes & References \\
\hline miRNA-212 & Cardiac hypertrophy & FOXO3 & (35) \\
\hline miRNA-30c & Cardiac hypertrophy & Cdc42 and Pak1 & (36) \\
\hline miRNA-30c \& 181 & Cardiac hypertrophy & p53 & (38) \\
\hline miRNA-199a & Cardiac hypertrophy & PGC-1 $1 \alpha$ & $(40)$ \\
\hline miRNA-200c & Cardiac hypertrophy & DUSP-1 & (39) \\
\hline miRNA-133a & Cardiac fibrosis & TGF-B1 & (43) \\
\hline miRNA-21 & Cardiac fibrosis & DUSP-8 & $(46)$ \\
\hline miRNA-1 & Cardiac apoptosis & IGF-1 & (62) \\
\hline miRNA-34a & Cardiac apoptosis & SIRT-1 & $(77)$ \\
\hline miRNA-483-3p & Cardiac apoptosis & IGF-1 & (64) \\
\hline miRNA-195 & Cardiac apoptosis & SIRT-1 & (65) \\
\hline miRNA-144 & Cardiac apoptosis & IRS & (66) \\
\hline miRNA-203 & Cardiac apoptosis & PIK3CA & (69) \\
\hline miRNA-532 & Cardiac apoptosis & ARC & (70) \\
\hline miRNA-30c & Cardiac autophagy & Beclin1 & (90) \\
\hline miRNA-30d & Cardiac pyroptosis & Foxo3A & (94) \\
\hline miRNA-9 & Cardiac pyroptosis & ELAVL1 & (95) \\
\hline miRNA-29a & Mitochondrial dysfunction & $\mathrm{PPAR} \alpha$ & (103) \\
\hline miRNA-210 & Mitochondrial dysfunction & ISCU1/2 & $(107)$ \\
\hline miRNA-141 & Mitochondrial dysfunction & SLC25A3 & $(108)$ \\
\hline miRNA-378 & Oxidative stress & ATP synthase & (109) \\
\hline miRNA-144 & Oxidative stress & Nrf2 & $(41)$ \\
\hline miRNA-301 & Electrical remodeling & $\mathrm{K} v 4.2$ & $(141)$ \\
\hline
\end{tabular}

translational potential as diagnostic and prognostic biomarkers and therapeutic modalities for DbCM. It was also shown
TABLE 2 | Deregulated IncRNAs in DbCM.

\begin{tabular}{lllc}
\hline IncRNAs & Process associated & Target genes & References \\
\hline MIAT & Hypertrophy; fibrosis & TLR4; TGF-B1 & $(49-51)$ \\
Kcnq1ot & Fibrosis; pyroptosis & TGF-B1 & $(52)$ \\
H19 & Apoptosis; autophagy & VDAC1; DIRAS3 & $(73,92)$ \\
MALAT 1 & Apoptosis & NLRP3; TGF-B1; ABCA1 & $(74-76)$ \\
HOTAIR & Apoptosis & SIRT-1 & $(77)$ \\
MEG3 & Apoptosis & PDCD 4 & $(78)$ \\
LUCAT1 & Apoptosis & CYP11B2 & $(80)$ \\
DCRF & Autophagy & PCDH17 & $(91)$
\end{tabular}

that HDACs are important regulators in the pathophysiology of DbCM. Inhibition of HDACs using inhibitors has shown promising data in the context of cardiac fibrosis. We have presented a detailed discussion on HDAC inhibitors as promising therapeutic targets for $\mathrm{DbCM}$. However, there is a need to investigate regulatory mechanisms such as chromatin modifications and circular RNAs as contributors to DbCM.

With the advancement in genomics and molecular biology techniques, such as transposase-accessible chromatin (ATAC) sequencing, deep sequencing, and ChIP-sequencing, highthroughput data on DNA methylomes can be generated. This genome-wide data will provide a comprehensive picture of $\mathrm{DbCM}$. The information, thus, acquired will help to understand the role of epigenetic modulators in DbCM in a pathway-specific manner. This review aims to help in understanding the role of various epigenetic factors in conjunction with specific pathways in DbCM. 


\section{AUTHOR CONTRIBUTIONS}

AM performed the data collection, data approval, manuscript drafting, and manuscript editing. MK performed data collection, manuscript drafting, and manuscript editing. $\mathrm{AB}$ performed data manuscript editing. RG performed manuscript editing during revision. All authors contributed to the article and approved the submitted version.

\section{REFERENCES}

1. Rubler S, Dlugash J, Yuceoglu YZ, Kumral T, Branwood AW, Grishman A. New type of cardiomyopathy associated with diabetic glomerulosclerosis. Am J Cardiol. (1972) 30:595-602. doi: 10.1016/0002-9149(72)90595-4

2. Kannel WB, Hjortland M, Castelli WP. Role of diabetes in congestive heart failure: the Framingham study. Am J Cardiol. (1974) 34:2934. doi: 10.1016/0002-9149(74)90089-7

3. Rydén L, Armstrong PW, Cleland JGF, Horowitz JD, Massie BM, Packer $\mathrm{M}$, et al. Efficacy and safety of high-dose lisinopril in chronic heart failure patients at high cardiovascular risk, including those with diabetes mellitus. Results from the ATLAS trial. Eur Heart J. (2000) 21:196778. doi: 10.1053/euhj.2000.2311

4. Shindler DM, Kostis JB, Yusuf S, Quinones MA, Pitt B, Stewart D, et al. Diabetes mellitus, a predictor of morbidity and mortality in the studies of left ventricular dysfunction (SOLVD) trials and registry. Am J Cardiol. (1996) 77:1017-20. doi: 10.1016/S0002-9149(97)89163-1

5. Thrainsdottir IS, Aspelund T, Thorgeirsson G, Gudnason V, Hardarson T, Malmberg K, et al. The association between glucose abnormalities and heart failure in the population-based Reykjavík study. Diabetes Care. (2005) 28:612-6. doi: 10.2337/diacare.28.3.612

6. Aronow WS, Ahn C. Incidence of heart failure in 2,737 older persons with and without diabetes mellitus. Chest. (1999) 115:867-8. doi: 10.1378/chest.115.3.867

7. Stratton IM, Adler AI, Neil HA, Matthews DR, Manley SE, Cull CA, et al. Association of glycaemia with macrovascular and microvascular complications of type 2 diabetes (UKPDS 35): prospective observational study. BMJ. (2000) 321:405. doi: 10.1136/bmj.321.7258.405

8. Lind M, Bounias I, Olsson M, Gudbjörnsdottir S, Svensson A-M, Rosengren A. Glycaemic control and incidence of heart failure in 20,985 patients with type 1 diabetes: an observational study. Lancet. (2011) 378:1406. doi: 10.1016/S0140-6736(11)60471-6

9. Westermeier F, Riquelme JA, Pavez M, Garrido V, Díaz A, Verdejo HE, et al. New molecular insights of insulin in diabetic cardiomyopathy. Front Physiol. (2016) 7:125. doi: 10.3389/fphys.2016.00125

10. Jia G, Hill MA, Sowers JR. Diabetic cardiomyopathy: an update of mechanisms contributing to this clinical entity. Circ Res. (2018) 122:62438. doi: 10.1161/CIRCRESAHA.117.311586

11. Jia G, Whaley-Connell A, Sowers JR. Diabetic cardiomyopathy: a hyperglycaemia- and insulin-resistance-induced heart disease. Diabetologia. (2018) 61:21-8. doi: 10.1007/s00125-017-4390-4

12. Khullar M, Cheema BS, Raut SK. Emerging evidence of epigenetic modifications in vascular complication of diabetes. Front Endocrinol. (2017) 8:237. doi: $10.3389 /$ fendo.2017.00237

13. Singh GB, Khanna S, Raut SK, Sharma S, Sharma R, Khullar M. DUSP1 gene expression is not regulated by promoter methylation in diabetesassociated cardiac hypertrophy. Ther Adv Cardiovasc Dis. (2017) 11:14754. doi: $10.1177 / 1753944717704590$

14. Shimizu M, Umeda K, Sugihara N, Yoshio H, Ino H, Takeda R, et al. Collagen remodelling in myocardia of patients with diabetes. J Clin Pathol. (1993) 46:32-6. doi: $10.1136 /$ jcp.46.1.32

15. Chiu J, Farhangkhoee H, Xu BY, Chen S, George B, Chakrabarti S. PARP mediates structural alterations in diabetic cardiomyopathy. $\mathrm{J} \mathrm{Mol} \mathrm{Cell}$ Cardiol. (2008) 45:385-93. doi: 10.1016/j.yjmcc.2008.06.009

16. Westermann D, Rutschow S, Jäger S, Linderer A, Anker S, Riad A, et al. Contributions of inflammation and cardiac matrix metalloproteinase activity

\section{ACKNOWLEDGMENTS}

$\mathrm{AM}, \mathrm{MK}$, and $\mathrm{AB}$ are thankful to the Department of Biotechnology for grant BT/PR27687/MED/12/823/2018. AM acknowledges PGIMER, Chandigarh for intramural grant 71/2Edu-16/525 for the support. RG acknowledges the CSIR Senior Research Associate (Scientists' pool) scheme for fellowship. We used BioRender online tool for the illustrations.

to cardiac failure in diabetic cardiomyopathy: the role of angiotensin type 1 receptor antagonism. Diabetes. (2007) 56:641-6. doi: 10.2337/db06-1163

17. Singh VP, Le B, Khode R, Baker KM, Kumar R. Intracellular angiotensin II production in diabetic rats is correlated with cardiomyocyte apoptosis, oxidative stress, and cardiac fibrosis. Diabetes. (2008) 57:3297-306. doi: 10.2337/db08-0805

18. Mizushige K, Yao L, Noma T, Kiyomoto H, Yu Y, Hosomi N, et al. Alteration in left ventricular diastolic filling and accumulation of myocardial collagen at insulin-resistant prediabetic stage of a type II diabetic rat model. Circulation. (2000) 101:899-907. doi: 10.1161/01.CIR.101.8.899

19. Bando YK, Murohara T. Diabetes-related heart failure. Circ J. (2014) 78:57683. doi: 10.1253/circj.CJ-13-1564

20. Jia G, Habibi J, DeMarco VG, Martinez-Lemus LA, Ma L, Whaley-Connell AT, et al. Endothelial mineralocorticoid receptor deletion prevents dietinduced cardiac diastolic dysfunction in females. Hypertension. (2015) 66:1159-67. doi: 10.1161/HYPERTENSIONAHA.115.06015

21. Huynh K, McMullen JR, Julius TL, Tan JW, Love JE, Cemerlang N, et al. Cardiac-specific IGF-1 receptor transgenic expression protects against cardiac fibrosis and diastolic dysfunction in a mouse model of diabetic cardiomyopathy. Diabetes. (2010) 59:1512-20. doi: 10.2337/db09-1456

22. Van Linthout S, Seeland U, Riad A, Eckhardt O, Hohl M, Dhayat $\mathrm{N}$, et al. Reduced MMP-2 activity contributes to cardiac fibrosis in experimental diabetic cardiomyopathy. Basic Res Cardiol. (2008) 103:31927. doi: 10.1007/s00395-008-0715-2

23. Bowden MA, Tesch GH, Julius TL, Rosli S, Love JE, Ritchie RH. Earlier onset of diabesity-Induced adverse cardiac remodeling in female compared to male mice. Obesity. (2015) 23:1166-77. doi: 10.1002/oby.21072

24. Galderisi M, Anderson KM, Wilson PW, Levy D. Echocardiographic evidence for the existence of a distinct diabetic cardiomyopathy (the Framingham Heart Study). Am J Cardiol. (1991) 68:859. doi: 10.1016/0002-9149(91)90716-X

25. Devereux RB, Roman MJ, Paranicas M, O’Grady MJ, Lee ET, Welty TK, et al. Impact of diabetes on cardiac structure and function: the strong heart study. Circulation. (2000) 101:2271-6. doi: 10.1161/01.CIR.101.19.2271

26. Dawson A, Morris AD, Struthers AD. The epidemiology of left ventricular hypertrophy in type 2 diabetes mellitus. Diabetologia. (2005) 48:19719. doi: 10.1007/s00125-005-1896-y

27. Bugger H, Abel ED. Molecular mechanisms of diabetic cardiomyopathy. Diabetologia. (2014) 57:660-71. doi: 10.1007/s00125-014-3171-6

28. Huynh K, Bernardo BC, McMullen JR, Ritchie RH. Diabetic cardiomyopathy: mechanisms and new treatment strategies targeting antioxidant signaling pathways. Pharmacol Ther. (2014) 142:375-415. doi: 10.1016/j.pharmthera.2014.01.003

29. Rosenkranz AC, Hood SG, Woods RL, Dusting GJ, Ritchie RH. Btype natriuretic peptide prevents acute hypertrophic responses in the diabetic rat heart. Diabetes. (2003) 52:2389-95. doi: 10.2337/diabetes.52. 9.2389

30. Sundgren NC, Giraud GD, Schultz JM, Lasarev MR, Stork PJS, Thornburg KL. Extracellular signal-regulated kinase and phosphoinositol3 kinase mediate IGF-1 induced proliferation of fetal sheep cardiomyocytes. Am J Physiol Regul Integr Comp Physiol. (2003) 285:R1481-9. doi: 10.1152/ajpregu.00232.2003

31. Jia G, Habibi J, Aroor AR, Hill MA, DeMarco VG, Lee LE, et al. Enhanced endothelium epithelial sodium channel signaling prompts left ventricular diastolic dysfunction in obese female mice. Metabolism. (2018) 78:6979. doi: 10.1016/j.metabol.2017.08.008 
32. Feng B, Chen S, Chiu J, George B, Chakrabarti S. Regulation of cardiomyocyte hypertrophy in diabetes at the transcriptional level. Am J Physiol Endocrinol Metab. (2008) 294:E111926. doi: $10.1152 /$ ajpendo.00029.2008

33. Hua Y, Zhang Y, Dolence J, Shi G-P, Ren J, Nair S. Cathepsin K knockout mitigates high-fat diet-induced cardiac hypertrophy and contractile dysfunction. Diabetes. (2013) 62:498-509. doi: 10.2337/db12-0350

34. Costantino S, Paneni F, Lüscher TF, Cosentino F. MicroRNA profiling unveils hyperglycaemic memory in the diabetic heart. Eur Heart J. (2016) 37:572-6. doi: 10.1093/eurheartj/ehv599

35. Ucar A, Gupta SK, Fiedler J, Erikci E, Kardasinski M, Batkai $\mathrm{S}$, et al. The miRNA-212/132 family regulates both cardiac hypertrophy and cardiomyocyte autophagy. Nat Commun. (2012) 3:1078. doi: $10.1038 /$ ncomms 2090

36. Raut SK, Kumar A, Singh GB, Nahar U, Sharma V, Mittal A, et al. miR$30 \mathrm{c}$ mediates upregulation of $\mathrm{Cdc} 42$ and Pak1 in diabetic cardiomyopathy. Cardiovasc Ther. (2015) 33:89-97. doi: 10.1111/1755-5922.12113

37. Su M, Wang J, Wang C, Wang X, Dong W, Qiu W, et al. MicroRNA-221 inhibits autophagy and promotes heart failure by modulating the p27/CDK2/mTOR axis. Cell Death Differ. (2015) 22:986-99. doi: 10.1038/cdd.2014.187

38. Raut SK, Singh GB, Rastogi B, Saikia UN, Mittal A, Dogra N, et al. miR-30c and miR-181a synergistically modulate p53-p21 pathway in diabetes induced cardiac hypertrophy. Mol Cell Biochem. (2016) 417:191203. doi: 10.1007/s11010-016-2729-7

39. Singh GB, Raut SK, Khanna S, Kumar A, Sharma S, Prasad $\mathrm{R}$, et al. MicroRNA-200c modulates DUSP-1 expression in diabetes-induced cardiac hypertrophy. Mol Cell Biochem. (2017) 424:1-11. doi: 10.1007/s11010-016-2838-3

40. Yan H, Wang H, Zhu X, Huang J, Li Y, Zhou K, et al. Adeno-associated virus-mediated delivery of anti-miR-199a tough decoys attenuates cardiac hypertrophy by targeting PGC-1alpha. Mol Ther Nucleic Acids. (2021) 23:406-17. doi: 10.1016/j.omtn.2020.11.007

41. Yu M, Liu Y, Zhang B, Shi Y, Cui L, Zhao X. Inhibiting microRNA144 abates oxidative stress and reduces apoptosis in hearts of streptozotocin-induced diabetic mice. Cardiovasc Pathol. (2015) 24:375-81. doi: 10.1016/j.carpath.2015.06.003

42. Chavali V, Tyagi SC, Mishra PK. MicroRNA-133a regulates DNA methylation in diabetic cardiomyocytes. Biochem Biophys Res Commun. (2012) 425:668-72. doi: 10.1016/j.bbrc.2012.07.105

43. Chen S, Puthanveetil P, Feng B, Matkovich SJ, Dorn GW, Chakrabarti S. Cardiac miR-133a overexpression prevents early cardiac fibrosis in diabetes. J Cell Mol Med. (2014) 18:415-21. doi: 10.1111/jcmm.12218

44. Kambis TN, Shahshahan HR, Kar S, Yadav SK, Mishra PK. Transgenic expression of miR-133a in the diabetic akita heart prevents cardiac remodeling and cardiomyopathy. Front Cardiovasc Med. (2019) 6:45. doi: $10.3389 /$ fcvm.2019.00045

45. Reddy S, Hu D-Q, Zhao M, Blay E, Sandeep N, Ong S-G, et al. miR-21 is associated with fibrosis and right ventricular failure. JCI Insight. (2017) 2:e91625. doi: 10.1172/jci.insight.91625

46. Liu S, Li W, Xu M, Huang H, Wang J, Chen X. Micro-RNA 21Targets dual specific phosphatase 8 to promote collagen synthesis in high glucosetreated primary cardiac fibroblasts. Can J Cardiol. (2014) 30:168999. doi: 10.1016/j.cjca.2014.07.747

47. Kumar A, Raut SK, Saikia UN, Sharma R, Khullar M. Abstract 15227: microrna-21 contributes to diabetic cardiomyopathy associated cardiac fibrosis. Circulation. (2011) 124:A15227. doi: 10.1161/circ.124.suppl_21.A15227

48. Statello L, Guo C-J, Chen L-L, Huarte M. Gene regulation by long noncoding RNAs and its biological functions. Nat Rev Mol Cell Biol. (2021) 22:96-118. doi: 10.1038/s41580-020-00315-9

49. Zhu X-H, Yuan Y-X, Rao S-L, Wang P. LncRNA MIAT enhances cardiac hypertrophy partly through sponging miR-150. Eur Rev Med Pharmacol Sci. (2016) 20:3653-60.

50. Li Y, Wang J, Sun L, Zhu S. LncRNA myocardial infarctionassociated transcript (MIAT) contributed to cardiac hypertrophy by regulating TLR4 via miR-93. Eur J Pharmacol. (2018) 818:508-17. doi: 10.1016/j.ejphar.2017.11.031
51. Qu X, Du Y, Shu Y, Gao M, Sun F, Luo S, et al. MIAT Is a Pro-fibrotic long non-coding RNA governing cardiac fibrosis in post-infarct myocardium. Sci Rep. (2017) 7:42657. doi: 10.1038/srep42657

52. Yang F, Qin Y, Lv J, Wang Y, Che H, Chen X, et al. Silencing long non-coding RNA Kcnq1otl alleviates pyroptosis and fibrosis in diabetic cardiomyopathy. Cell Death Dis. (2018) 9:1000. doi: 10.1038/s41419-018-1029-4

53. Chen Y, Du J, Zhao YT, Zhang L, Lv G, Zhuang S, et al. Histone deacetylase (HDAC) inhibition improves myocardial function and prevents cardiac remodeling in diabetic mice. Cardiovasc Diabetol. (2015) 14:99. doi: 10.1186/s12933-015-0262-8

54. Xu Z, Tong Q, Zhang Z, Wang S, Zheng Y, Liu Q, et al. Inhibition of HDAC3 prevents diabetic cardiomyopathy in OVE26 mice via epigenetic regulation of DUSP5-ERK1/2 pathway. Clin Sci. (2017) 131:184157. doi: $10.1042 / C S 20170064$

55. Dong F, Ren J. Fidarestat improves cardiomyocyte contractile function in $\mathrm{db} / \mathrm{db}$ diabetic obese mice through a histone deacetylase Sir2-dependent mechanism. J Hypertens. (2007) 25:2138-47. doi: 10.1097/HJH.0b013e32828626d1

56. Christidi E, Brunham LR. Regulated cell death pathways in doxorubicin-induced cardiotoxicity. Cell Death Dis. (2021) 12:339. doi: 10.1038/s41419-021-03614-x

57. Frustaci A, Kajstura J, Chimenti C, Jakoniuk I, Leri A, Maseri A, et al. Myocardial cell death in human diabetes. Circ Res. (2000) 87:112332. doi: 10.1161/01.RES.87.12.1123

58. Hu X, Bai T, Xu Z, Liu Q, Zheng Y, Cai L. pathophysiological fundamentals of diabetic cardiomyopathy. Compr Physiol. (2017) 7:693711. doi: 10.1002/cphy.c160021

59. Boudina S, Abel ED. Diabetic cardiomyopathy, causes and effects. Rev Endocr Metab Disord. (2010) 11:31-9. doi: 10.1007/s11154-010-9131-7

60. Fiordaliso F, Li B, Latini R, Sonnenblick EH, Anversa P, Leri A, et al. Myocyte death in streptozotocin-induced diabetes in rats is angiotensin II- dependent. Lab Invest. (2000) 80:513-27. doi: 10.1038/labinvest.3780057

61. Kobayashi S, Zhao F, Kobayashi T, Hagiwara M, Kaminaris A, Li C, et al. Hyperglycemia-induced cardiomyocyte death is mediated by lysosomal membrane injury and aberrant expression of cathepsin D. Biochem Biophys Res Commun. (2020) 523:239-45. doi: 10.1016/j.bbrc.2019.12.051

62. Yu X-Y, Song Y-H, Geng Y-J, Lin Q-X, Shan Z-X, Lin S-G, et al. Glucose induces apoptosis of cardiomyocytes via microRNA-1 and IGF-1. Biochem Biophys Res Commun. (2008) 376:548-52. doi: 10.1016/j.bbrc.2008.09.025

63. Fomison-Nurse I, Saw EEL, Gandhi S, Munasinghe PE, Van Hout I, Williams MJA, et al. Diabetes induces the activation of pro-ageing miR-34a in the heart, but has differential effects on cardiomyocytes and cardiac progenitor cells. Cell Death Different. (2018) 25: 13361349. doi: 10.1038/s41418-017-0047-6

64. Qiao Y, Zhao Y, Liu Y, Ma N, Wang C, Zou J, et al. miR-483$3 \mathrm{p}$ regulates hyperglycaemia-induced cardiomyocyte apoptosis in transgenic mice. Biochem Biophys Res Commun. (2016) 477:541-7. doi: 10.1016/j.bbrc.2016.06.051

65. Zheng D, Ma J, Yu Y, Li M, Ni R, Wang G, et al. Silencing of miR-195 reduces diabetic cardiomyopathy in C57BL/6 mice. Diabetologia. (2015) 58:1949-58. doi: 10.1007/s00125-015-3622-8

66. Karolina DS, Armugam A, Tavintharan S, Wong MTK, Lim SC, Sum CF, et al. MicroRNA 144 impairs insulin signaling by inhibiting the expression of insulin receptor substrate 1 in type 2 diabetes mellitus. PLoS ONE. (2011) 6:e22839. doi: 10.1371/journal.pone.0022839

67. Song Y, Mai H, Lin Y, Wang Y, Wang X, Gu S. MiR-144 affects proliferation and apoptosis of high glucose-induced AC16 cardiomyocytes by regulating CTRP3/JNK signaling. In J Clin Exp Pathol. (2020) 13:142-52.

68. Tao L, Huang X, Xu M, Yang L, Hua F. MiR-144 protects the heart from hyperglycemia-induced injury by regulating mitochondrial biogenesis and cardiomyocyte apoptosis. The FASEB Journal. (2020) 34:21732197. doi: 10.1096/fj.201901838R

69. Yang $\mathrm{X}, \mathrm{Li} \mathrm{X}$, Lin $\mathrm{Q}, \mathrm{Xu}$ Q. Up-regulation of microRNA-203 inhibits myocardial fibrosis and oxidative stress in mice with diabetic cardiomyopathy through the inhibition of PI3K/Akt signaling pathway via PIK3CA. Gene. (2019) 715:143995. doi: 10.1016/j.gene.2019.143995

70. Chandrasekera DNK, Neale JPH, van Hout I, Rawal S, Coffey S, Jones GT, et al. Upregulation of microRNA-532 enhances 
cardiomyocyte apoptosis in the diabetic heart. Apoptosis.

(2020) 25:388-99. doi: 10.1007/s10495-020-01609-1

71. Shan Z-X, Lin Q-X, Deng C-Y, Zhu J-N, Mai L-P, Liu J-L, et al. miR-1/miR-206 regulate Hsp60 expression contributing to glucosemediated apoptosis in cardiomyocytes. FEBS Lett. (2010) 584:3592600. doi: 10.1016/j.febslet.2010.07.027

72. Guo Y, Feng X, Wang D, Kang X, Zhang L, Ren H, et al. Long non-coding RNA: a key regulator in the pathogenesis of diabetic cardiomyopathy. Front Cardiovasc Med. (2021) 8:655598. doi: 10.3389/fcvm.2021.655598

73. Li X, Wang H, Yao B, Xu W, Chen J, Zhou X. IncRNA H19/miR-675 axis regulates cardiomyocyte apoptosis by targeting VDAC1 in diabetic cardiomyopathy. Sci Rep. (2016) 6:36340. doi: 10.1038/srep36340

74. Zhang $\mathrm{M}, \mathrm{Gu} \mathrm{H}$, Xu W, Zhou X. Down-regulation of IncRNA MALAT1 reduces cardiomyocyte apoptosis and improves left ventricular function in diabetic rats. Int $J$ Cardiol. (2016) 203:214-6. doi: 10.1016/j.ijcard.2015.10.136

75. Che H, Wang Y, Li H, Li Y, Sahil A, Lv J, et al. Melatonin alleviates cardiac fibrosis via inhibiting lncRNA MALAT1/miR-141-mediated NLRP3 inflammasome and TGF- $\beta 1 /$ Smads signaling in diabetic cardiomyopathy. FASEB J. (2020) 34:5282-98. doi: 10.1096/fj.201902692R

76. Wang C, Liu G, Yang H, Guo S, Wang H, Dong Z, et al. MALAT1-mediated recruitment of the histone methyltransferase EZH2 to the microRNA-22 promoter leads to cardiomyocyte apoptosis in diabetic cardiomyopathy. Sci Total Environ. (2021) 766:142191. doi: 10.1016/j.scitotenv.2020.142191

77. Gao L, Wang X, Guo S, Xiao L, Liang C, Wang Z, et al. LncRNA HOTAIR functions as a competing endogenous RNA to upregulate SIRT1 by sponging miR-34a in diabetic cardiomyopathy. J Cell Physiol. (2019) 234:4944-58. doi: 10.1002/jcp.27296

78. Chen Y, Zhang Z, Zhu D, Zhao W, Li F. Long non-coding RNA MEG3 serves as a ceRNA for microRNA-145 to induce apoptosis of AC16 cardiomyocytes under high glucose condition. Biosci Rep. (2019) 39:BSR20190444. doi: 10.1042/BSR20190444

79. Li Q, Li P, Su J, Liu S, Yang X, Yang Y, et al. LncRNA NKILA was upregulated in diabetic cardiomyopathy with early prediction values. Exp Ther Med. (2019) 18:1221-5. doi: 10.3892/etm.2019.7671

80. Yin Y, Yang Z-F, Li X-H, Zhou L-Q, Zhang Y-J, Yang B. Knockdown of long non-coding RNA LUCAT1 reverses high glucose-induced cardiomyocyte injury via targeting CYP11B2. Eur Rev Med Pharmacol Sci. (2019) 23:85605. doi: 10.26355/eurrev_201910_19171

81. Yu X-Y, Geng Y-J, Liang J-L, Lin Q-X, Lin S-G, Zhang S, et al. High levels of glucose induce apoptosis in cardiomyocyte via epigenetic regulation of the insulin-like growth factor receptor. Exp Cell Res. (2010) 316:29039. doi: 10.1016/j.yexcr.2010.07.004

82. Özcan U, Cao Q, Yilmaz E, Lee A-H, Iwakoshi NN, Özdelen E, et al. Endoplasmic reticulum stress links obesity, insulin action, and type 2 diabetes. Science. (2004) 306:457-61. doi: 10.1126/science.11 03160

83. Guo R, Liu W, Liu B, Zhang B, Li W, Xu Y. SIRT1 suppresses cardiomyocyte apoptosis in diabetic cardiomyopathy: an insight into endoplasmic reticulum stress response mechanism. Int J Cardiol. (2015) 191:36-45. doi: 10.1016/j.ijcard.2015.04.245

84. Puthanveetil P, Zhang D, Wang Y, Wang F, Wan A, Abrahani A, et al. Diabetes triggers a PARP1 mediated death pathway in the heart through participation of FoxO1. J Mol Cell Cardiol. (2012) 53:67786. doi: 10.1016/j.yjmcc.2012.08.013

85. Kanamori H, Takemura G, Goto K, Tsujimoto A, Mikami A, Ogino A, et al. Autophagic adaptations in diabetic cardiomyopathy differ between type 1 and type 2 diabetes. Autophagy. (2015) 11:114660. doi: 10.1080/15548627.2015.1051295

86. Bravo-San Pedro JM, Kroemer G, Galluzzi L. Autophagy and mitophagy in cardiovascular disease. Circ Res. (2017) 120:1812-24. doi: 10.1161/CIRCRESAHA.117.311082

87. Dewanjee S, Vallamkondu J, Kalra RS, John A, Reddy PH, Kandimalla R. Autophagy in the diabetic heart: a potential pharmacotherapeutic target in diabetic cardiomyopathy. Ageing Res Rev. (2021) 68:101338. doi: 10.1016/j.arr.2021.101338

88. Mellor KM, Bell JR, Young MJ, Ritchie RH, Delbridge LMD. Myocardial autophagy activation and suppressed survival signaling is associated with insulin resistance in fructose-fed mice. J Mol Cell Cardiol. (2011) 50:103543. doi: 10.1016/j.yjmcc.2011.03.002

89. Xie Z, Lau K, Eby B, Lozano P, He C, Pennington B, et al. Improvement of cardiac functions by chronic metformin treatment is associated with enhanced cardiac autophagy in diabetic OVE26 mice. Diabetes. (2011) 60:1770-8. doi: 10.2337/db10-0351

90. Chen C, Yang S, Li H, Yin Z, Fan J, Zhao Y, et al. Mir30c is involved in diabetic cardiomyopathy through regulation of cardiac autophagy via BECN1. Mol Ther Nucleic Acids. (2017) 7:127-39. doi: 10.1016/j.omtn.2017.03.005

91. Feng Y, Xu W, Zhang W, Wang W, Liu T, Zhou X. LncRNA DCRF regulates cardiomyocyte autophagy by targeting miR-551b-5p in diabetic cardiomyopathy. Theranostics. (2019) 9:4558-66. doi: 10.7150/thno.31052

92. Zhuo C, Jiang R, Lin X, Shao M. LncRNA H19 inhibits autophagy by epigenetically silencing of DIRAS3 in diabetic cardiomyopathy. Oncotarget. (2016) 8:1429-37. doi: 10.18632/oncotarget.13637

93. Zeng C, Wang R, Tan H. Role of pyroptosis in cardiovascular diseases and its therapeutic implications. Int J Biol Sci. (2019) 15:1345-57. doi: 10.7150/ijbs.33568

94. Li X, Du N, Zhang Q, Li J, Chen X, Liu X, et al. MicroRNA-30d regulates cardiomyocyte pyroptosis by directly targeting foxo3a in diabetic cardiomyopathy. Cell Death Dis. (2014) 5:e1479. doi: 10.1038/cddis.2014.430

95. Jeyabal P, Thandavarayan RA, Joladarashi D, Suresh Babu S, Krishnamurthy S, Bhimaraj A, et al. MicroRNA-9 inhibits hyperglycemia-induced pyroptosis in human ventricular cardiomyocytes by targeting ELAVL1. Biochem Biophys Res Commun. (2016) 471:423-9. doi: 10.1016/j.bbrc.2016.02.065

96. Kim J-A, Wei Y, Sowers JR. Role of mitochondrial dysfunction in insulin resistance. Circ Res. (2008) 102:40114. doi: 10.1161/CIRCRESAHA.107.165472

97. Jia G, DeMarco VG, Sowers JR. Insulin resistance and hyperinsulinaemia in diabetic cardiomyopathy. Nat Rev Endocrinol. (2016) 12:144-153. doi: 10.1038/nrendo.2015.216

98. Anderson EJ, Kypson AP, Rodriguez E, Anderson CA, Lehr EJ, Neufer PD. Substrate-specific derangements in mitochondrial metabolism and redox balance in the atrium of the type 2 diabetic human heart. J Am Coll Cardiol. (2009) 54:1891-8. doi: 10.1016/j.jacc.2009.07.031

99. Anderson EJ, Rodriguez E, Anderson CA, Thayne K, Chitwood WR, Kypson AP. Increased propensity for cell death in diabetic human heart is mediated by mitochondrial-dependent pathways. Am J Physiol Heart Circ Physiol. (2011) 300:H118-24. doi: 10.1152/ajpheart.00932.2010

100. Shaikh S, Troncoso R, Criollo A, Bravo-Sagua R, García L, Morselli E, et al. Regulation of cardiomyocyte autophagy by calcium. Am J Physiol Endocrinol Metab. (2016) 310:E587-96. doi: 10.1152/ajpendo.00374.2015

101. Peng X-P, Huang L, Liu Z-H. miRNA-133a attenuates lipid accumulation via TR4-CD36 pathway in macrophages. Biochimie. (2016) 127:7985. doi: 10.1016/j.biochi.2016.04.012

102. Pelsers MMAL, Lutgerink JT, van Nieuwenhoven FA, Tandon NN, van der Vusse GJ, Arends J-W, et al. A sensitive immunoassay for rat fatty acid translocase (CD36) using phage antibodies selected on cell transfectants: abundant presence of fatty acid translocase/CD36 in cardiac and red skeletal muscle and up-regulation in diabetes. Biochem J. (1999) 337:40714. doi: 10.1042/bj3370407

103. Liang F, Wang F, Zhang S, Gardner DG. Peroxisome proliferator activated receptor (PPAR) $\alpha$ agonists inhibit hypertrophy of neonatal rat cardiac myocytes. Endocrinology. (2003) 144:4187-94. doi: 10.1210/en.2002-0217

104. Liang J, Liu C, Qiao A, Cui Y, Zhang H, Cui A, et al. MicroRNA-29a-c decrease fasting blood glucose levels by negatively regulating hepatic gluconeogenesis. J Hepatol. (2013) 58:535-42. doi: 10.1016/j.jhep.2012.10.024

105. Diao X, Shen E, Wang X, Hu B. Differentially expressed microRNAs and their target genes in the hearts of streptozotocin-induced diabetic mice. Mol Med Rep. (2011) 4:633-40. doi: 10.3892/mmr.2011.489

106. Greco S, Fasanaro P, Castelvecchio S, D’Alessandra Y, Arcelli D, Di Donato $\mathrm{M}$, et al. MicroRNA dysregulation in diabetic ischemic heart failure patients. Diabetes. (2012) 61:1633-41. doi: 10.2337/db11-0952

107. Chan SY, Zhang Y-Y, Hemann C, Mahoney CE, Zweier JL, Loscalzo J. MicroRNA-210 controls mitochondrial metabolism during hypoxia by repressing the iron-sulfur cluster assembly proteins ISCU1/2. Cell Metab. (2009) 10:273-84. doi: 10.1016/j.cmet.2009.08.015 
108. Baseler WA, Thapa D, Jagannathan R, Dabkowski ER, Croston TL, Hollander JM. miR-141 as a regulator of the mitochondrial phosphate carrier (Slc25a3) in the type 1 diabetic heart. Am J Physiol Cell Physiol. (2012) 303:C1244-51. doi: 10.1152/ajpcell.00137.2012

109. Jagannathan R, Thapa D, Nichols CE, Shepherd DL, Stricker JC, Croston TL, et al. Translational regulation of the mitochondrial genome following redistribution of mitochondrial microRNA in the diabetic heart. Circ Cardiovasc Genet. (2015) 8:785802. doi: 10.1161/CIRCGENETICS.115.001067

110. Li B, Carey M, Workman JL. The role of chromatin during transcription. Cell. (2007) 128:707-19. doi: 10.1016/j.cell.2007.01.015

111. Wu Y, Leng Y, Meng Q, Xue R, Zhao B, Zhan L, Xia Z. Suppression of excessive histone deacetylases activity in diabetic hearts attenuates myocardial ischemia/reperfusion injury via mitochondria apoptosis pathway. J Diabetes Res. (2017) 2017:8208065. doi: 10.1155/2017/8208065

112. Fang W, Wang C, He Y, Zhou Y, Peng X, Liu S. Resveratrol alleviates diabetic cardiomyopathy in rats by improving mitochondrial function through PGC-1 $\alpha$ deacetylation. Acta Pharmacol Sin. (2018) 39:5973. doi: 10.1038 /aps. 2017.50

113. Ma S, Feng J, Zhang R, Chen J, Han D, Li X, et al. SIRT1 Activation by resveratrol alleviates cardiac dysfunction via mitochondrial regulation in diabetic cardiomyopathy mice. Oxid Med Cell Long. (2017) 2017:e4602715. doi: 10.1155/2017/4602715

114. Lee T-I, Kao Y-H, Tsai W-C, Chung C-C, Chen Y-C, Chen YJ. HDAC inhibition modulates cardiac PPARs and fatty acid metabolism in diabetic cardiomyopathy. PPAR Res. (2016) 2016:5938740. doi: 10.1155/2016/5938740

115. Teshima Y, Takahashi N, Nishio S, Saito S, Kondo H, Fukui A, et al. Production of reactive oxygen species in the diabetic heart. Roles of mitochondria and NADPH oxidase. Circ J. (2014) 78:3006. doi: 10.1253/circj.CJ-13-1187

116. Giacco F, Brownlee M. Oxidative stress and diabetic complications. Circ Res. (2010) 107:1058-70. doi: 10.1161/CIRCRESAHA.110.223545

117. Rolo AP, Palmeira CM. Diabetes and mitochondrial function: role of hyperglycemia and oxidative stress. Toxicol Appl Pharmacol. (2006) 212:16778. doi: $10.1016 /$ j.taap.2006.01.003

118. Shen X, Zheng S, Thongboonkerd V, Xu M, Pierce WM Jr, Klein JB, et al. Cardiac mitochondrial damage and biogenesis in a chronic model of type 1 diabetes. Am J Physiol. (2004) 287:E896-905. doi: 10.1152/ajpendo.00047.2004

119. Yildirim SS, Akman D, Catalucci D, Turan B. Relationship between downregulation of miRNAs and increase of oxidative stress in the development of diabetic cardiac dysfunction: junctin as a target protein of miR-1. Cell Biochem Biophys. (2013) 67:1397-408. doi: 10.1007/s12013-013-9672-y

120. Magenta A, Greco S, Gaetano C, Martelli F. Oxidative stress and microRNAs in vascular diseases. Int J Mol Sci. (2013) 14:1731946. doi: 10.3390/ijms140917319

121. Shen E, Diao X, Wang X, Chen R, Hu B. micrornas involved in the mitogen-activated protein kinase cascades pathway during glucoseinduced cardiomyocyte hypertrophy. Am J Pathol. (2011) 179:63950. doi: 10.1016/j.ajpath.2011.04.034

122. Kumar S, Kim Y-R, Vikram A, Naqvi A, Li Q, Kassan M, et al. Sirtuin1regulated lysine acetylation of p66Shc governs diabetes-induced vascular oxidative stress and endothelial dysfunction. Proc Natl Acad Sci USA. (2017) 114:1714-9. doi: 10.1073/pnas.1614112114

123. Wei D, Loeken MR. Increased DNA methyltransferase 3b (Dnmt3b)mediated $\mathrm{CpG}$ island methylation stimulated by oxidative stress inhibits expression of a gene required for neural tube and neural crest development in diabetic pregnancy. Diabetes. (2014) 63:3512-22. doi: 10.2337/db14-0231

124. Mortuza R, Chen S, Feng B, Sen S, Chakrabarti S. High glucose induced alteration of SIRTs in endothelial cells causes rapid aging in a p300 and FOXO regulated pathway. PLoS ONE. (2013) 8:e54514. doi: 10.1371/journal.pone.0054514

125. Tomaselli GF, Marbán E. Electrophysiological remodeling in hypertrophy and heart failure. Cardiovasc Res. (1999) 42:27083. doi: 10.1016/S0008-6363(99)00017-6
126. Kaprielian R, Wickenden AD, Kassiri Z, Parker TG, Liu PP, Backx PH. Relationship between $\mathrm{K}+$ channel down-regulation and $[\mathrm{Ca} 2+] \mathrm{i}$ in rat ventricular myocytes following myocardial infarction. J Physiol. (1999) 517(Pt 1):229-45. doi: 10.1111/j.1469-7793.1999.0229z.x

127. Näbauer M, Kääb S. Potassium channel down-regulation in heart failure. Cardiovasc Res. (1998) 37:324-34. doi: 10.1016/S0008-6363(97)00274-5

128. Rozanski GJ, Xu Z, Zhang K, Patel KP. Altered K+ current of ventricular myocytes in rats with chronic myocardial infarction. Am J Physiol Heart Circ Physiol. (1998) 274:H259-65. doi: 10.1152/ajpheart.1998.274.1.H259

129. Xu L, Patel KP, Rozanski GJ. Metabolic basis of decreased transient outward $\mathrm{K}+$ current in ventricular myocytes from diabetic rats. Am J Physiol Heart Circ Physiol. (1996) H2190-6. doi: 10.1152/ajpheart.1996.271.5.H2190

130. Shimoni Y, Ewart HS, Severson D. Insulin stimulation of rat ventricular K+ currents depends on the integrity of the cytoskeleton. J Physiol. (1999) 514 (Pt 3):735-745. doi: 10.1111/j.1469-7793.1999.735ad.x

131. Shimoni Y, Ewart HS, Severson D. Type I and II models of diabetes produce different modifications of $\mathrm{K}+$ currents in rat heart: role of insulin. J Physiol. (1998) 507(Pt 2):485-96. doi: 10.1111/j.1469-7793.1998.485bt.x

132. Chambers JB, Sampson MJ, Sprigings DC, Jackson G. QT prolongation on the electrocardiogram in diabetic autonomic neuropathy. Diabetic Med. (1990) 7:105-10. doi: 10.1111/j.1464-5491.1990.tb01342.x

133. Ninkovic VM, Ninkovic SM, Miloradovic V, Stanojevic D, Babic M, Giga $\mathrm{V}$, et al. Prevalence and risk factors for prolonged QT interval and QT dispersion in patients with type 2 diabetes. Acta Diabetol. (2016) 53:73744. doi: 10.1007/s00592-016-0864-y

134. Bellavere F, Ferri M, Guarini L, Bax G, Piccoli A, Cardone C, et al. Prolonged QT period in diabetic autonomic neuropathy: a possible role in sudden cardiac death? Heart. (1988) 59:379-83. doi: 10.1136/hrt.59.3.379

135. Brown DW, Giles WH, Greenlund KJ, Valdez R, Croft JB. Impaired fasting glucose, diabetes mellitus, and cardiovascular disease risk factors are associated with prolonged QTc duration. results from the third national health and nutrition examination survey. J Cardiovasc Risk. (2001) 8:22733. doi: $10.1177 / 174182670100800407$

136. Tse G, Lai ETH, Tse V, Yeo JM. Molecular and electrophysiological mechanisms underlying cardiac arrhythmogenesis in diabetes mellitus. $J$ Diabetes Res. (2016) 2016:e2848759. doi: 10.1155/2016/2848759

137. Hegyi B, Bers DM, Bossuyt J. CaMKII signaling in heart diseases: emerging role in diabetic cardiomyopathy. J Mol Cell Cardiol. (2019) 127:24659. doi: 10.1016/j.yjmcc.2019.01.001

138. Lengyel C, Virág L, Kovács PP, Kristóf A, Pacher P, Kocsis E, et al. Role of slow delayed rectifier $\mathrm{K}+$-current in QT prolongation in the alloxan-induced diabetic rabbit heart. Acta Physiol. (2008) 192:35968. doi: 10.1111/j.1748-1716.2007.01753.x

139. Torres-Jacome J, Gallego M, Rodríguez-Robledo JM, Sanchez-Chapula JA, Casis O. Improvement of the metabolic status recovers cardiac potassium channel synthesis in experimental diabetes. Acta Physiol. (2013) 207:44759. doi: 10.1111/apha.12043

140. Gallego M, Fernández D, Ahyayauch H, Casis E, Casis O. Reduced calmodulin expression accelerates transient outward potassium current inactivation in diabetic rat heart. CPB. (2008) 22:625-34. doi: 10.1159/000185546

141. Panguluri SK, Tur J, Chapalamadugu KC, Katnik C, Cuevas J, Tipparaju SM. MicroRNA-301a mediated regulation of $\mathrm{Kv} 4.2$ in diabetes: identification of key modulators. PLOS ONE. (2013) 8:e60545. doi: 10.1371/journal.pone.0060545

142. Arnold N, Koppula PR, Gul R, Luck C, Pulakat L. Regulation of cardiac expression of the diabetic marker microRNA miR-29. PLoS ONE. (2014) 9:e103284. doi: 10.1371/journal.pone.0103284

143. Harris LG, Wang SH, Mani SK, Kasiganesan H, Chou CJ, Menick DR. Evidence for a non-canonical role of HDAC5 in regulation of the cardiac Ncxl and Bnp genes. Nucleic Acids Res. (2016) 44:36107. doi: $10.1093 / \mathrm{nar} / \mathrm{gkv} 1496$

144. Chandrasekaran S, Peterson RE, Mani SK, Addy B, Buchholz AL, Xu L, et al. Histone deacetylases facilitate sodium/calcium exchanger up-regulation in adult cardiomyocytes. FASEB J. (2009) 23:3851-64. doi: 10.1096/fj.09-132415

145. Lehmann LH, Jebessa ZH, Kreusser MM, Horsch A, He T, Kronlage M, et al. A proteolytic fragment of histone deacetylase 4 protects the heart from 
failure by regulating the hexosamine biosynthetic pathway. Nat Med. (2018) 24:62-72. doi: $10.1038 / \mathrm{nm} .4452$

146. Syren P, Rahm A-K, Schweizer PA, Bruehl C, Katus HA, Frey $\mathrm{N}$, et al. Histone deacetylase 2-dependent ventricular electrical remodeling in a porcine model of early heart failure. Life Sci. (2021) 281:119769. doi: 10.1016/j.lfs.2021.119769

147. Freundt JK, Frommeyer G, Spieker T, Wötzel F, Grotthoff JS, Stypmann J, et al. Histone deacetylase inhibition by Entinostat for the prevention of electrical and structural remodeling in heart failure. BMC Pharmacol Toxicol. (2019) 20:16. doi: 10.1186/s40360-019-0294-x

148. Qin H-T, Li H-Q, Liu F. Selective histone deacetylase small molecule inhibitors: recent progress and perspectives. Expert Opin Ther Pat. (2017) 27:621-36. doi: 10.1080/13543776.2017.1276565

149. Kim HJ, Rowe M, Ren M, Hong J-S, Chen P-S, Chuang D-M. Histone deacetylase inhibitors exhibit anti-inflammatory and neuroprotective effects in a rat permanent ischemic model of stroke: multiple mechanisms of action. J Pharmacol Exp Ther. (2007) 321:892-901. doi: 10.1124/jpet.107.120188

150. Marks PA. Histone deacetylase inhibitors: a chemical genetics approach to understanding cellular functions. Biochim Biophys Acta. (2010) 1799:71725. doi: 10.1016/j.bbagrm.2010.05.008

151. Liu N, Zhuang S. Treatment of chronic kidney diseases with histone deacetylase inhibitors. Front Physiol. (2015) 6:121. doi: 10.3389/fphys.2015.00121

152. Eckschlager $\mathrm{T}$, Plch J, Stiborova $\mathrm{M}$, Hrabeta J. Histone deacetylase inhibitors as anticancer drugs. Int J Mol Sci. (2017) 18:E1414. doi: 10.3390/ijms18071414

153. Choi SY, Piao ZH, Jin L, Kim JH, Kim GR, Ryu Y, et al. Piceatannol attenuates renal fibrosis induced by unilateral ureteral obstruction via downregulation of histone deacetylase 4/5 or p38-MAPK signaling. PLoS ONE. (2016) 11:e0167340. doi: 10.1371/journal.pone.0167340

154. Li M, Zheng Y, Yuan H, Liu Y, Wen X. Effects of dynamic changes in histone acetylation and deacetylase activity on pulmonary fibrosis. Int Immunopharmacol. (2017) 52:272-80. doi: 10.1016/j.intimp.2017. 09.020

155. Korfei M, Skwarna S, Henneke I, MacKenzie B, Klymenko O, Saito $S$, et al. Aberrant expression and activity of histone deacetylases in sporadic idiopathic pulmonary fibrosis. Thorax. (2015) 70:102232. doi: 10.1136/thoraxjnl-2014-206411

156. Kis K, Liu X, Hagood JS. Myofibroblast differentiation and survival in fibrotic disease. Expert Rev Mol Med. (2011) 13:e27. doi: 10.1017/S1462399411001967

157. Kang S-H, Seok YM, Song M, Lee H-A, Kurz T, Kim I. Histone deacetylase inhibition attenuates cardiac hypertrophy and fibrosis through acetylation of mineralocorticoid receptor in spontaneously hypertensive rats. Mol Pharmacol. (2015) 87:782-91. doi: 10.1124/mol.114.096974

158. Liu Y, Li S, Zhang Z, Lv Z, Jiang H, Tan X, Liu F. Effects of valproic acid on sympathetic activity and left ventricularmyocardial remodelling in rats during pressure overload. Turk J Med Sci. (2017) 47:16511660. doi: 10.3906/sag-1704-142

159. Zhang Y, Gao F, Tang Y, Xiao J, Li C, Ouyang Y, et al. Valproic acid regulates Ang II-induced pericyte-myofibroblast trans-differentiation via MAPK/ERK pathway. Am J Transl Res. (2018) 10:1976-89.

160. Scholz B, Schulte JS, Hamer S, Himmler K, Pluteanu F, Seidl MD, et al. HDAC (Histone Deacetylase) inhibitor valproic acid attenuates atrial remodeling and delays the onset of atrial fibrillation in mice. Circ Arrhythm Electrophysiol. (2019) 12:e007071. doi: 10.1161/CIRCEP.118.007071

161. Kao Y-H, Liou J-P, Chung C-C, Lien G-S, Kuo C-C, Chen S-A, et al. Histone deacetylase inhibition improved cardiac functions with direct antifibrotic activity in heart failure. Int J Cardiol. (2013) 168:417883. doi: $10.1016 /$ j.ijcard.2013.07.111

162. Nural-Guvener HF, Zakharova L, Nimlos J, Popovic S, Mastroeni D, Gaballa MA. HDAC class I inhibitor, Mocetinostat, reverses cardiac fibrosis in heart failure and diminishes $\mathrm{CD} 90+$ cardiac myofibroblast activation. Fibrogenesis Tissue Repair. (2014) 7:10. doi: 10.1186/1755-1536-7-10

163. Tao H, Yang J-J, Hu W, Shi K-H, Li J. HDAC6 promotes cardiac fibrosis progression through suppressing RASSF1A expression. Cardiology. (2016) 133:18-26. doi: 10.1159/000438781

Conflict of Interest: The authors declare that the research was conducted in the absence of any commercial or financial relationships that could be construed as a potential conflict of interest.

Publisher's Note: All claims expressed in this article are solely those of the authors and do not necessarily represent those of their affiliated organizations, or those of the publisher, the editors and the reviewers. Any product that may be evaluated in this article, or claim that may be made by its manufacturer, is not guaranteed or endorsed by the publisher.

Copyright $\odot 2021$ Mittal, Garg, Bahl and Khullar. This is an open-access article distributed under the terms of the Creative Commons Attribution License (CC BY). The use, distribution or reproduction in other forums is permitted, provided the original author(s) and the copyright owner(s) are credited and that the original publication in this journal is cited, in accordance with accepted academic practice. No use, distribution or reproduction is permitted which does not comply with these terms. 